\title{
A transformação social nos discursos da cena empreendedora social brasileira: processos comunicacionais e regimes de convocação na midia digital $^{1}$
}

\author{
Vander Casaqui ${ }^{2}$ \\ Escola Superior de Propaganda e Marketing - ESPM, São Paulo, Brasil ${ }^{3}$ \\ vcasaqui@yahoo.com.br \\ Recibido: 10 de diciembre de 2014 \\ Aceptado: 27 de abril de 2015 \\ Disponible en linea: 30 de noviembre de 2015
}

\footnotetext{
Artigo de reflexão, que apresenta resultados parciais de um projeto de investigação sobre o tema do empreendedorismo social, em perspectiva analitica e crítica. Este artigo é desenvolvido no contexto do projeto "Narrativas para transformar o mundo: sentidos do empreendedorismo social nos contextos português e brasileiro", iniciado como pesquisa de pós-doutoramento realizada entre janeiro e junho de 2013 na Faculdade de Ciências Sociais e Humanas da Universidade Nova de Lisboa (FCSH-UNL). Nesse período, a investigação contou com bolsa de estágio pós-doutoral no exterior da CAPES (processo BEX no. 10542-12-4). Essa pesquisa continua a ser desenvolvida no Programa de Pós-Graduação em Comunicação e Práticas de Consumo da ESPM, no triênio 2013-2015.

2 Doutor em Ciências da Comunicação pela Universidade de São Paulo.

3 Professor do Programa de Pós-Graduação em Comunicação e Práticas de Consumo da ESPM.
} 


\section{A transformação social nos discursos da cena empreendedora social brasileira: processos comunicacionais e regimes de convocação na mídia digital}

\section{Resumo}

Neste estudo, derivado de pesquisa de pós-doutoramento sobre o tema do empreendedorismo social, desenvolvemos uma análise de discursos de projetos brasileiros em sua presença na mídia digital. O problema colocado por essa pesquisa é: quais os significados da transformação social, do engajamento e da participação cidadã, sob a ótica dos discursos do empreendedorismo social no Brasil? Discutimos o caráter de uma mudança condicionada à 'sustentabilidade' dos projetos, no choque entre a visão de negócios e a vocação para o 'bem comum'; assim como tratamos dos projetos de sociedade articulados em torno da figura do empreendedor social. O percurso teórico reflete sobre o novo espírito do capitalismo, a cultura empreendedora e o campo semântico do empreendedorismo social. O tratamento do corpus da pesquisa é baseado na análise crítica do discurso proposta por Fairclough (2001). Palavras-chave: empreendedorismo social; comunicação e discurso; transformação social; consumo; cultura empreendedora; economia capitalista

\section{La transformación social en los discursos de la escena emprendedora social brasileña: procesos comunicacionales y regimenes de convocación en los medios digitales}

\section{Resumen}

En este estudio, derivado de una investigación de postdoctorado sobre el tema del emprenderismo social, desarrollamos un análisis de discurso de proyectos brasileños y su presencia en los medios digitales. El problema planteado por esta investigación es: ¿cuáles son los significados de la transformación social, del compromiso y de la participación ciudadana, bajo la óptica de los discursos del emprendimiento social en Brasil? Discutimos el carácter de un cambio condicionado a la 'sustentabilidad' de los proyectos, en choque entre la visión de negocios y la vocación hacia el 'bien común'; así como observamos los proyectos de sociedad articulados en torno a la figura del emprendedor social. El transcurso teórico reflexiona sobre el nuevo espíritu del capitalismo, la cultura emprendedora y el campo semántico del emprendimiento social. El tratamiento del corpus de la investigación está basado en el análisis crítico del discurso propuesto por Fairclough (2001).

Palabras clave: emprendimiento social; comunicación y discurso; transformación social; consumo; cultura emprendedora; economía capitalista

\section{The social transformation in the discourse of the Brazilian social entrepreneur scene: communication processes and convening regimes in digital media}

\section{Summary}

In this study, derived from a postdoctoral research on the subject of social undertaking, a discourse analysis of Brazilian projects and their presence in digital media was developed. The problem posed by this research is: What are the meanings of social transformation, commitment and citizen participation from the perspective of social undertaking discourses in Brazil? We discuss the nature of a change determined by the 'sustainability' of projects, opposed to a business vision and the vocation towards the "common good"; and we analyze society projects articulated around the figure of the social entrepreneur. The theoretical framework is focused on the new spirit of capitalism, the entrepreneurial culture and the semantic field of social undertaking. The treatment of the corpus of this research is based on the discourse critical analysis proposed by Fairclough (2001).

Keywords: social undertaking; communication and discourse; social transformation; consumption; entrepreneurial culture; capitalism 


\section{Introdução}

Nosso trabalho parte da hipótese de que o tema do empreendedorismo social é de grande interesse para o campo da comunicação, uma vez que sua cena é constituída e alimentada por processos discursivos, por estratégias midiáticas, por regimes de visibilidade. Agenciadores globais e atores locais, sujeitos e grupos interessados no tema, pautas públicas e espaços ocupados na mídia caracterizam a complexa teia comunicacional a partir da qual o empreendedor social é significado e legitimado, aqui e agora. Devido ao crescente destaque de empreendedores sociais na sociedade brasileira contemporânea, observamos como esse agente incorpora os sentidos da mudança social, em discursos apoiados em regimes de convocação biopolítica (Prado, 2013), por meio dos quais a sociedade é conclamada ao engajamento e à mobilização.

Segundo Quintão (2012), o empreendedorismo social se estabelece na confluência de duas tradições históricas derivadas da consolidação do sistema capitalista. Por um lado, há a figura do empreendedor, o promotor da destruição criadora (Schumpeter, 1961) que alimenta o avanço do capitalismo liberal. Por outro, o trabalho em torno da emergência da 'questão social', da mobilização da sociedade civil para amenizar os efeitos da Revolução Industrial sobre os trabalhadores e excluídos do sistema. No decorrer desse artigo, refletimos sobre as intersecções, choques e paradoxos representados pela denominação 'empreendedor social'.

Em trabalho anterior (Casaqui, 2014), desenvolvemos um levantamento bibliográfico em torno da constituição histórica do conceito de empreendedorismo social, bem como localizamos o estado da arte da discussão. Talvez por ser um tema relativamente recente, que ganha impulso no contexto do século XXI, nossa pesquisa detectou alguns poucos trabalhos que tratam do empreendedorismo social em perspectiva crítica, e nenhum vinculado ao campo da comunicação. Há, no entanto, uma profusão de artigos e alguns livros que apresentam o empreendedor social na perspectiva da gestão ou da economia. Mesmo quando se propõe uma espécie de análise social, trata-se da perspectiva dos realizadores ou de adesão ao seu ideário -sem o distanciamento 
crítico e a visão sistêmica, necessários para a compreensão do papel atribuído a esse agente em nosso tempo.

\section{Comunicação, inovação social e novas perspectivas do empreendedorismo}

A proposta de tematização das "práticas comunicativas, criatividade e novos desafios" feita para esta edição da Revista Universitas Humanística nos direciona à observação da cena empreendedora social a partir desses eixos. Como práticas comunicativas, entendemos a leitura do empreendedorismo social a por meio dos discursos que constituem e caracterizam as atividades das organizações, dos agentes de seu campo, em plataformas midiáticas como a internet, como é o caso desse estudo. Nesse sentido, vemos que a emergência do conceito de empreendedor social é um processo essencialmente comunicacional. Esse processo é baseado na elaboração de uma forma de nominalização que, por sua vez, vai gerar novas práticas, mas também vai transformar os significados e denominações de tantas outras que existiam anteriormente e passam a ser identificadas por esse conceito. Como defende Fairclough (2001, p. 227): “a nominalização transforma processos e atividades em estados e objetos, e ações concretas em abstratas". Apoiamo-nos na abordagem da análise critica do discurso de Fairclough para compreender como práticas sociais e discursivas se conectam e interinfluenciam, especialmente em cenários de transformação, de mudança social, nos quais o autor localiza sua perspectiva analítica.

A noção de criatividade pode parecer pouco evidente em uma primeira leitura, mas está intrinsecamente relacionada com nosso objeto. O empreendedorismo social está articulado com a noção de inovação social, que por sua vez representa a criatividade aplicada à concepção de soluções para os problemas sociais -percebidos como oportunidades para novos projetos. A inovação social faz parte de uma mesma rede semântica, de uma constelação de termos originados nas práticas do mercado capitalista, que ganham novos significados quando acompanhados do termo 'social'. Dessa forma, inovação, 
negócio, economia, entre outros termos, ao se tornarem 'sociais', são aproximados da noção de bem comum, de algo cujo objetivo final seria a contribuição a melhorias na sociedade, e não o lucro, que está na base da economia capitalista.

A ideia de uma sociedade aberta às iniciativas de qualquer cidadão, que seja capaz de perceber uma oportunidade e articular a partir daí um negócio, de propor alguma mercadoria ou serviço que inove dado mercado e conquiste novos consumidores, compõe a mítica do self made man. Toda uma cultura baseada na concorrência e legitimada pelo discurso da meritocracia se sustenta nessa ideia da oportunidade para 'qualquer um' -o que não quer dizer 'para todos', como lembra um personagem do filme No, de Pablo Larraín (2012), sobre o plebiscito que decidiu pelo fim da era do ditador chileno Augusto Pinochet no poder, no ano de 1988.

O self made man seria o herói da cultura capitalista, o destruidor criativo identificado por Schumpeter (1961), ainda nas primeiras décadas do século XX. Inovação e negócio são partes de um mesmo processo do capitalismo, em que o empreendedor é figura chave. No âmbito desta pesquisa, os novos desafios (o terceiro termo evocado pela temática da revista) estão associados ao discurso que desloca o empreendedor para a resolução de problemas sociais, com maior eficácia e alcance que as iniciativas do Estado (ou Primeiro Setor) e que as tradicionais organizações identificadas com o chamado Terceiro Setor (organizações não governamentais, misericórdias, entidades filantrópicas, de caridade e voluntariado). A prática empreendedora de mercado, com o objetivo de transformar o mundo, une a performance técnica com a vocação para o bem comum. O Segundo Setor, que abriga a iniciativa privada, serve como modelo ideal da técnica adotada para resolver problemas sociais.

As práticas comunicacionais são centrais para legitimar e difundir o conceito de empreendedorismo social na sociedade, na busca de seu campo por reconhecimento, poder simbólico e capital social (Bourdieu, 2009). Os agentes do campo investem na entrada em cena midiática, desde a mídia digital até espaços na mídia tradicional (especialmente 
em programas de caráter jornalístico), para defender seu lugar autêntico e a importância de sua atuação na teia social. A inovação empreendedora passa a ser inovação social; o processo de conceber projetos, ideias, de viabilizá-los por meio de planos de negócios (também entendidos como 'sociais'), é a atividade criativa gerada pelo mercado capitalista, agora dedicada ao novo desafio de 'mudar o mundo'. Conforme definição apresentada pela Escola Design Thinking, sediada em São Paulo, capital:

Inovação social é uma nova solução para um problema social que é mais eficaz, eficiente e sustentável que as soluções existentes ou que cria valor para a sociedade como um todo, em vez de somente para um indivíduo ou organização privada. (Stanford Social Innovation Review, s.d.)

A atividade do empreendedor social pressupõe uma lógica de mercado. Diante da falência do Estado Social, considerada a realidade de países como os da Comunidade Europeia; ou da inexistência histórica desse Estado de Bem-Estar Social (Wellfare State) em paises chamados 'em desenvolvimento' (como é o caso do Brasil), o empreendedor social é situado retoricamente como alternativa à incapacidade dos governos de sanar os problemas sociais que afligem a população, ou das iniciativas históricas da sociedade civil, como as instituições de caridade, filantrópicas e de voluntariado. O discurso da eficácia, da performance técnica do empreendedor é posicionado como um marco, um tipo de revolução na forma de tratar as questões sociais. É interessante destacar que, apesar de haver um discurso universalizante padronizador do perfil do empreendedor social, seu campo de atuação se articula localmente e seus significados são demarcados por questões econômicas, culturais e históricas específicas.

No contexto de Portugal, lugar que abrigou o início dessa pesquisa de pós-doutoramento, a atividade empreendedora social serve como resposta, certo antídoto que alia estratégias argumentativas e o exemplo de algumas práticas bem sucedidas, a todo um cenário de crise que atinge gravemente esse país. Uma crise, especialmente dramática em relação à falta de postos no mercado de trabalho, 
que ultrapassa as questões econômicas para atingir a autoestima da população, as perspectivas de futuro, as apostas na capacidade de Portugal encontrar saídas e se reerguer. Como diz a pesquisadora portuguesa Mónica Lopes, o empreendedorismo, em suas diversas facetas, transformou-se na "panaceia que solucionará os graves problemas do desemprego desencadeados pela crise", por meio de formas de apoio à inovação e aos chamados "autoempregos" gerados por novos negócios, bem como, supostamente, "atenuará os impactos da crise através das iniciativas solidárias do microempreendedorismo, do empreendedorismo social e do empreendedorismo económico solidário" (Lopes, 2012, p. 87).

Em sua obra clássica sobre o processo histórico de constituição da economia capitalista de mercado, intitulada A grande transformação (editada pela primeira vez em 1944), Polanyi define economia de mercado. Em suas palavras:

Uma economia de mercado significa um sistema autorregulável de mercados, em termos ligeiramente mais técnicos, é uma economia dirigida pelos preços do mercado e nada além dos preços do mercado. Um tal sistema, capaz de organizar a totalidade da vida econômica sem qualquer ajuda ou interferência externa, certamente mereceria ser chamado de autorregulável. Essas condições preliminares devem ser suficientes para revelar a natureza inteiramente sem precedentes de tal acontecimento na história da raça humana. (Polanyi, 2012, p. 45)

No campo do empreendedorismo social, é recorrente o discurso sobre a necessidade da sustentabilidade econômica dos projetos, o que remete diretamente à questão da autorregulação- se não de um mercado tradicional, de um mercado de ideias, conforme discute Angenot (2010). Ideias para resolver problemas sociais devem se adequar à lógica neoliberal, pois os projetos precisam afirmar, de forma recorrente, a capacidade sustentável de suas operações. O modelo de negócios é o fator predominante na avaliação de um empreendimento social; os projetos são adequados para atuar em um mercado, mesmo que social, para disputar com outras propostas. A competitividade se faz presente nos 
inúmeros concursos voltados para o apoio ao empreendedorismo social. Esta realidade sugere que as verbas destinadas à ação sustentável estão reservadas para os projetos mais adequados à combinação entre resolução de problemas sociais e plano de negócios eficaz -muitas vezes com a predominância deste último para definição dos 'vencedores'.

Polanyi sinaliza a passagem dessa vertente econômica liberal a um sistema de crenças, a um credo liberal que ainda alimenta a leitura do livre mercado como a tábua de salvação da humanidade:

O liberalismo econômico foi o princípio organizador de uma sociedade engajada na criação de um sistema de mercado. Nascido como mera propensão em favor de métodos não burocráticos, ele evoluiu para uma fé verdadeira na salvação secular do homem através de um mercado autorregulável. Um tal fanatismo resultou do súbito agravamento da tarefa pela qual ele se responsabilizara: a magnitude dos sofrimentos a serem infligidos a pessoas inocentes, assim como o amplo alcance das mudanças entrelaçadas que a organização da nova ordem envolvia. (Polanyi, 2012, p. 151)

Nos discursos que representam o campo do empreendedorismo social, está implícita a fé na capacidade de um tipo de "mercado social", composto pelas iniciativas atomizadas de pessoas e pequenos coletivos de agentes. Uma fé traduzida em posturas afirmativas, no diagnóstico mágico que aponta para um movimento em curso, uma 'revolução' projetada no futuro e simultaneamente celebrada por seus resultados já alcançados. Uma espécie de "utopia pragmática", sustentada pela estratégia de tornar visiveis as iniciativas consideradas exemplares.

\section{Análise de casos do empreendedorismo social no Brasil}

A perspectiva metodológica adotada para este estudo, conforme indicado anteriormente, está baseada na análise crítica do discurso de 
Fairclough (2001). O autor propõe um método de análise multidimensional, que relaciona textos, discursos e práticas sociais. Esta abordagem interessa a esta pesquisa, uma vez que tratamos de textos que articulam a ideologia de um campo (do empreendedorismo social) com as práticas derivadas de sua atuação. O discurso sobre a prática é manifestado como um projeto de sociedade, relacionado com uma noção de transformação social. Fairclough localiza sua metodologia em ambientes de mudança social; a mudança em questão é uma formação discursiva recorrente no campo estudado. Dessa forma, buscamos compreender como textos, discursos e práticas produzem significados sobre o que é o processo de transformação capitaneado pelo empreendedor social.

Em relação ao procedimento de seleção do corpus analisado, extraído da mídia digital, partimos também de premissas do estudo do discurso social de Angenot (2010). O autor propõe a análise dos encadeamentos discursivos que representam uma totalidade, que ultrapassam seus aspectos singulares para identificar as 'forças sociais' e suas regularidades discursivas. O critério de seleção dos textos é a presença do discurso sobre a transformação relacionado com a atuação do empreendedor social. Temos como objetivo analisar como esse agente é construído por um projeto de mudança social, marcado ideologicamente pela ideia de sociedade empreendedora concebida por Drucker (2011).

A associação entre empreendedorismo social e a imagem do 'transformador' é recorrente: uma das maiores organizações globais dessa cena, a Ashoka, chama os empreendedores sociais de changemakers. Um dos projetos que analisamos, o "Imagina na Copa" trata seus agentes como transformadores. Diante da constatação da incidência de termos como 'transformação' e 'mudança' identificados com o campo do empreendedorismo social, lançamos um olhar crítico para os discursos que mobilizam o campo semântico da transformação social, tendo

O Imagina na Copa é um projeto, situado na mídia digital, que recolheu, produziu e publicizou histórias de empreendedores sociais brasileiros, apresentados como modelos do país imaginado como melhor no futuro. Seu nome é uma inversão positiva das críticas que a população brasileira fazia durante os preparativos para a Copa do Mundo de futebol, realizada em 2014 no país. Diante de algum problema, como no caso de atrasos nos aeroportos, a frase original que se podia ouvir nas ruas era: "se agora está assim, imagina na copa": (Cabral, Campanatti, Ribeiro y Pereira, s.d.) 
como pano de fundo a cultura empreendedora, a lógica da performance (Ehrenberg, 2010), diretamente associada ao modus operandi do mercado neoliberal. Ou seja, no cenário neoliberal em que concorrer e vencer pela 'meritocracia' é regra generalizada, difundida no senso comum, os sujeitos assumem para si a responsabilidade da superação de obstáculos e de seus próprios limites, a fim de se tornarem competitivos e alcançarem o sucesso. A alta performance empreendedora é valorizada pela cultura correspondente a esse cenário.

A contextualização da cultura empreendedora e do empreendedorismo social, em nossa pesquisa, é desenvolvida em alinhamento com a tese do novo espírito do capitalismo (Boltanski, \& Chiapello, 2009). De acordo com os autores, que elaboram uma perspectiva histórica do espírito do capitalismo, nas últimas décadas do século $\mathrm{XX}$ tivemos a emergência da cultura empreendedora como paradigma que não se refere unicamente ao mundo do trabalho, é transportado para a vida como um todo. O espírito do capitalismo está relacionado com as lógicas de justificação do sistema, que se adequa ciclicamente ao universo de expectativas dos sujeitos. Nesse cenário, a retórica do capitalismo se ajusta para motivar, para produzir engajamento adequado às demandas dos novos tempos. E que tempos são esses em que vivemos? Se considerarmos os discursos produzidos pela agência brasileira de pesquisa de tendências e comportamento Box1824, vivemos a era em que uma nova geração, chamada Millenials ou Geração Y, emerge como paradigma do futuro. Um futuro que já acontece agora, em que os jovens procuram viver o mundo do trabalho por meio de uma lógica de autonomia, liberdade e felicidade. De sua investigação que prioriza as novas gerações com idade para inserção no mercado de trabalho, a Box1824 extrai um perfil que, em sua tese, será o agente transformador, moldado para liderar, inspirar toda uma geração de brasileiros: o jovem-ponte. Suas características se ajustam ao homem conexionista, que corresponde ao novo espírito do capitalismo (Boltanski y Chiapello, 2009). De acordo com a pesquisa do Projeto Sonho Brasileiro, o jovem-ponte tem como característica principal a aptidão de recolher ideias em seu trânsito por diferentes grupos e redistribui-las na sociedade, "conectando redes e pessoas que nunca se falariam. Este jovem funciona como um catalisador de ideias, gerando 
um novo tipo de influência, que se dá pela transversalidade" (Projeto Sonho Brasileiro, 2011).

Para Boltanski e Chiapello (2009, p. 466), o homem identificado com o mundo conexionista é flexivel, adaptável, capaz de "tratar sua própria pessoa como um texto que poderia ser traduzido para diferentes línguas" para explorar redes e circular por universos distintos. Em última instância, sua atuação tem como fim a "utilização estratégica de relações" (p. 460), ou seja, a exploração produtiva dos contatos, numa forma de mercantilização das relações, mesmo que seja com o fim de 'mudar o mundo', de causas sociais, e não em proveito próprio, como argumentam os discursos do campo do empreendedorismo social. Essa questão é um dos pontos frágeis desse discurso, uma vez que há outros capitais, que não o econômico, atribuídos ao empreendedor social, como o capital simbólico ou o capital social - ainda mais no momento em que esse agente ganha espaço na mídia brasileira, em um processo de celebrização associado às ações em torno do 'bem comum'. Concursos como o Prêmio Folha Empreendedor Social, organizado pela Folha da São Paulo, o principal jornal brasileiro, em cooperação com a Fundação Schwab (uma das mais importantes organizações que agenciam o empreendedorismo social no mundo), oferecem visibilidade, resultam na obtenção de premiações simbólicas e financeiras, servindo, mesmo que involuntariamente, a uma espécie de culto à personalidade, a uma celebrização de seus responsáveis.

É importante destacar que o propósito de "mudar o mundo", relacionado ao empreendedorismo social, traduz a utopia da sociedade empreendedora, termo cunhado por Peter Drucker (2011), autor do campo da gestão e do marketing. Segundo o autor, a efetiva mudança da sociedade seria levada a cabo pelos empreendedores, sem rupturas revolucionárias. Essa concepção de Drucker aponta para a lógica da reforma, da sustentabilidade do próprio sistema capitalista -eliminando qualquer possibilidade de um outro mundo possivel, ou de uma outra economia, que proponha alternativas ao modelo estabelecido como hegemônico em nosso tempo. Em última instância, o capitalismo se recoloca como via única, inclusive para sua própria superação, o que é uma ideia paradoxal. 
O modelo do jovem conexionista, ou o jovem-ponte, construído pela pesquisa da Box1824, é o ponto de partida para algumas das iniciativas mais importantes do empreendedorismo social brasileiro recente, mais especificamente da cena da cidade de São Paulo, a maior capital do país e uma das maiores metrópoles do mundo. Dentre elas, está o já citado projeto Imagina na Copa. Neste ponto, discutimos um dos exemplos mais representativos dessa cena: a Rede Atados ${ }^{5}$. Seus fundadores foram finalistas do Prêmio Folha Empreendedor Social 2014, o que ampliou sua notoriedade. Sua proposta como empreendimento social é constituir um território, uma rede digital cujo objetivo é dar visibilidade a iniciativas brasileiras e assim mobilizar voluntários para trabalhar nesses projetos. Como diz a apresentação do próprio projeto,

O Atados é uma plataforma social que conecta pessoas e organizações, facilitando o engajamento nas mais diversas possibilidades de voluntariado. O fortalecimento dessa rede e a mobilização de voluntários ampliam o impacto das organizações e transformam pessoas e comunidades. (Atados, s.d.)

A participação nessa rede serve à santificação pelas obras (Weber, 2004) de seus aliados: a noção do 'bem' é deslocada de seu sentido 'comum', comunitário, do produto da ação, para também qualificar o ser que age. Ou seja, quem se associa à rede é considerado "do bem", como atesta a frase em destaque no topo da página principal do projeto: "Uma rede do bem, para fazer o bem!", bem como seu slogan: "Atados -juntando gente boa". O projeto de transformação se baseia no conexionismo, e os mentores da rede Atados se auto intitulam articuladores dessa utopia baseada na conexão- uma utopia pragmática, de "gente que faz":

O encontro entre voluntários e organizações, representado aqui em Atos Voluntários são possibilidades de experiências e vínculos. E é nesse encontro que o Atados acredita. Nesse encontro que afeta e modifica. Que aproxima e cria vínculos.

5 Rede Atados Pode ser encontrado em: atados.com.br 
Essa conexão ajuda a alimentar uma rede de pessoas que tem em comum a busca do bem coletivo e da harmonização das nossas relações - com nós mesmos e com o mundo. (Atados, s.d.)

A fé no contato, na aproximação de sujeitos, no conexionismo salvador, reelabora a noção do liberalismo e seu credo liberal, discutidos por Polanyi (2012): a autorregulação da sociedade, com vistas a uma harmonia coletiva, tem como pano de fundo um projeto de sociedade idealizado pelo encontro de sujeitos 'do bem', em polarização com 'o mal'. Nesse aspecto, ecoa, de certa maneira, o emblemático slogan tradicional do Google; "Don't be evil”. Esse polo contrário fica sugerido pelo trecho da apresentação do projeto "Juntar ao invés de separar. Conciliar ao invés de romper. Cooperar ao invés de competir". O alvo da atribuição negativa poderia ser o individualismo, o conflito de interesses entre grupos sociais distintos, a competição mercadológica. A proposta de transformação no discurso da rede Atados é baseada na propagação de um saber, de um conhecimento a ser difundido nessa rede de gestos e pessoas conectados, que promoveria a união, o pacto social amplo e harmônico. Um tipo de revelação mágica, que guarda relação intertextual com a doutrinação religiosa.

Outra iniciativa que rendeu à sua idealizadora, Lorrana Scarpioni, o posto de finalista do Prêmio Folha Empreendedor Social 2014, foi a plataforma Bliive, cujo nome é uma corruptela da palavra believe (acredite, na língua inglesa, o que reitera o campo discursivo religioso mencionado acima). O processo de funcionamento do projeto é assim explicado na página principal do projeto, em três etapas:

Você oferece uma experiência. Por exemplo, uma aula de guitarra durante uma hora.

Pela hora oferecida você recebe um TimeMoney, a moeda de troca da rede.

Agora você pode trocar seu TimeMoney pelo que quiser. 
A mercadorização das relações, transformadas em créditos de horas, em moeda própria que permite transações entre usuários da plataforma, remete à lógica de trocas mercantilista. A alternativa ao uso do dinheiro ganha a aura de revolução, e o processo de transformação não tem como objetivo específico a resolução de um problema social. Pode atender a gostos, a desejos, quereres, à demanda por 'experiências'. Em tese, propõe trocas entre sujeitos que tem algo a oferecer, de interesse de outros, e que não são excluídos do acesso à mídia digital, o que significa certo patamar social acima das condições precárias das camadas mais baixas da sociedade. Estabelece, enfim, novos olhares para as relações entre pessoas, agora potencialmente traduziveis em mercadorias para consumo e pagas em horas de trabalho. A 'revolução', mesmo que promotora de alguns deslocamentos mimetiza o paradigma capitalista baseado na associação entre mercadorias e pessoas. A consagrada frase 'Tempo é dinheiro' sustenta a estratégia criativa do negócio, identificado como "social" - ao menos no contexto do concurso de Empreendedorismo Social promovido pela Folha de São Paulo.

\section{Do mercado de ideias à volta ao mercado tradicional -a publicidade de Chivas Regal}

Um caso recente, que serve à reflexão sobre os deslocamentos e incorporações do discurso do empreendedorismo social e sua aproximação com o mundo das celebridades, dos novos olimpianos (Morin, 2011) relacionados ao espírito do capitalismo como discute Ehrenberg, (2010), é a iniciativa da marca internacional de uísque Chivas. A noção de olimpiano, originalmente desenvolvida por Morin para tratar das estrelas correspondentes à cultura de massas, como as estrelas de cinema de meados do século XX, relaciona-se com os personagens que servem de modelo, para possível projeção-identificação dos sujeitos de sua época. Ehrenberg aponta que, na atualidade, o empreendedor ocupa esse espaço de modelo de cultura, por ter associada a si uma vida heroica, pois assume riscos, representa o sucesso e o exemplo a ser seguido pelos demais. O empreendedor social, nesse sentido, é celebrizado para 'inspirar' as práticas da sociedade em que vive. 
Chivas desenvolve, a partir de 2014, uma campanha mundial, desdobrada em ações locais, em torno da imagem do empreendedor social. O Brasil está entre os países escolhidos para compor esse mosaico de histórias de vidas exemplares (Buonanno, 2011), conectadas com o universo simbólico da marca. O slogan clássico de Chivas, 'Live with Chivalry', ou viva com cavalheirismo, transporta os códigos de distinção aristocrática em tempos passados para nossos dias. O discurso publicitário relaciona o consumo do uísque com um comportamento cavalheiresco de pessoas que iriam 'contra a corrente', no sentido contrário da multidão. O homem de Chivas não é um qualquer, mais um na 'massa'; sua superioridade é sugerida pela nobreza de seus atos e refinamento de seus gostos, representados em imagens que aliam capital econômico e cultural. Poder simbólico e econômico que subentendem o compartilhamento do gosto por Chivas como elo comum.

A relação da marca Chivas com o empreendedorismo social é uma iniciativa muito recente, e bastante curiosa na sua associação com esse campo. O filme global da campanha, intitulado 'Vença do jeito certo' lançado em novembro de 2014 , Chivas Regal (2014) -uma espécie de manifesto da marca-, estabelece a equação entre o sucesso e o 'propósito', termo recorrente no discurso associado à noção de bem comum. Um ator negro ${ }^{6}$, trajando blazer e camisa branca, em um ringue de boxe (cenário de luta, alegoria da competitividade do mercado capitalista), movimenta-se de um lado a outro e dialoga com a câmera, olhando para o observador construído pela mensagem. Seu discurso é muito explícito na significação do sucesso com um cariz social: "Dinheiro. Que função ele tem, se não para fazer o bem? [...] Nos tornamos a mudança que o mundo deseja ver".

Imagens de personagens que vão traduzir essa estratégia localmente aparecem no filme, como é o caso do ator brasileiro Marcos Palmeira, proprietário da Fazenda Vale das Palmeiras, dedicada à produção de alimentos orgânicos: "Pra mim é fundamental, fazer o lucro e fazer o bem. Eu acho que esse é o casamento do sucesso". Sua fala é sucedida pelo ator do início, que continua: "Isto é Chivalry. Viver não

6 Trata-se de Chiwetel Ejiofor, ator principal do filme 12 years of slave, produção norte-americana de 2013, que ganhou o Oscar de melhor filme em 2014, entre outros prêmios. 
como 'eles e nós' mas como 'todos nós". Mais adiante, surge uma pergunta na tela, em fundo preto e letras garrafais: "Se não a gente, então quem?". A frase final do filme é: "Desta vez, nós venceremos do jeito certo", sucedida do slogan tradicional da marca, 'Live with Chivalry'. Há um paradoxo fundamental, na oscilação entre a perspectiva igualitária, o "todos nós", mencionada rapidamente, e a afirmação dos eleitos, da distinção, do "nós" vocacionado ao sucesso 'com cavalheirismo'. O tom imperativo do discurso é a convocação para que esse grupo seleto assuma seu papel de liderança, de ascensão sobre os demais.

O representante desses líderes visionários, vencedores que obtêm o sucesso do jeito certo, na articulação brasileira da campanha é o ator Marcos Palmeira (mencionado acima), apresentado como modelo de empreendedor social. A página da rede Facebook da marca Chivas Regal Brasil traz a 'timeline biography' do ator, a sua 'história de vida' - na verdade, uma narrativa mítica que mostra o ator como um ser despertado para uma vocação, que alia sensibilidade, iniciativa e ousadia. Chivas utiliza a imagem do galã, conhecido nacionalmente por atuar em telenovelas da maior rede de televisão do Brasil, a Rede Globo, como garoto propaganda para afirmar a dimensão moral, o caráter do homem de negócios 'do bem' sobreposto à imagem do empreendedor social.

Na leitura de Chivas, mais do que resolver problemas sociais, o modelo agora é o do homem de negócios bem sucedido que promove também 'um impacto social positivo'. A narrativa do herói mostra como o ator de sucesso, originário de um extrato social favorecido economicamente para os padrões brasileiros, ousa arriscar em um projeto, um 'sonho': ser proprietário de uma fazenda e lá instalar a produção de alimentos orgânicos, de forma sustentável, incluindo a comercialização dos produtos em loja própria. O despertar de seus ideais se dá pelo contato, ainda na juventude, com uma tribo indígena. Essa inspiração, a 'semente empreendedora social', é apresentada como a grande lição de vida para que siga sua trajetória heroica, ao enfrentar todos os obstáculos pelo caminho, até chegar ao momento atual, no qual é celebrado como o exemplo vitorioso do homem que faz negócios, tem um propósito, obtém lucro e se preocupa com o lado social de sua atividade. Basicamente, o que está em questão na ini- 
ciativa de Marcos Palmeira e sua fazenda é uma lógica de fair trade, quer dizer, um negócio justo e vantajoso 'para todos', ao menos no plano discursivo. Nada que ultrapasse os limites de seu empreendimento, nenhum projeto de sociedade que evoque a dimensão política da transformação social. Em síntese: cuidar de si e 'pensar no outro'.

$\mathrm{Na}$ campanha analisada, o sucesso ainda se mantém como paradigma do imaginário liberal. O self made man é santificado por suas obras, na releitura do espírito protestante discutido por Weber (2004). O lucro e o sucesso aliados a 'fazer o bem', como oferecer um produto 'melhor' para seus clientes, assistência dentária a seus funcionários, cuidar da sustentabilidade e do equilíbrio ambiental em sua própria propriedade. O imaginário da transformação social, cooptado pelo mercado, é exemplar na comunicação da marca de uísque Chivas Regal e sua ressignificação do conceito de empreendedor social:

Empreendedores que sabem que um negócio próprio pode ser lucrativo, mas também pode (e deve) fazer bem para os outros. E vão atrás de seus sonhos.

Chivas acredita que os empreendedores sociais representam o sucesso no século XXI. E suas histórias merecem ser contadas. Por isso, escolhemos lançar no Facebook de Chivas a biografia de Marcos Palmeira, agricultor orgânico e ator. Dedicação, cavalheirismo, generosidade e coragem são as bases dessa história de sucesso! Cheers! ${ }^{7}$

Chivas propõe a definitiva sobreposição entre os termos 'empreendedor' e 'empreendedor social', abolindo a diferença que os separava em termos conceituais: o objetivo principal de atender à resolução ou amenizar um problema social é ultrapassado pelo sonho de um negócio lucrativo, mas que 'pode (e deve) fazer bem', sem que o 'bem' tenha qualquer compromisso com uma efetiva transformação da sociedade. O uísque se posiciona como símbolo do sucesso de quem faz bons negócios e tem o poder de cooptar para sua iniciativa a aura do 'bem comum'. Como revela uma das frases de Marcos Palmeira em sua 'timeline biography': "Se o meu negócio for lucrativo e, ao mesmo

7 Publicado na página da Chivas Regal Brasil do Facebook no dia 23 set. 2014. 
tempo, puder gerar impactos positivos na vida das pessoas, me considero um vencedor".

\section{Considerações finais}

Os regimes de convocação (Prado, 2013) ${ }^{8}$ da cena empreendedora social buscam mobilizar seguidores, voluntários, apoiadores, investidores sociais, por meio de uma estratégia de difusão de modelos de cultura (Morin, 2011), de exemplos de sucesso. Dessa forma, histórias de vida exemplares (Buonanno, 2011) ganham a mídia e se propagam com a legitimidade celebrada pela própria comunicação. A aura do bem comum constitui uma espécie de Olimpo, o patamar superior reservado aos lideres visionários. O projeto de sociedade sugere que a adesão às causas e as práticas de consumo delas derivadas é associada à ação cidadã, acessível a qualquer sujeito 'do bem'. A transformação social ganha diferentes matizes, tendo seus limites expandidos a cada novo discurso de cooptação, de deslocamento, de afirmação de um agente que busca reafirmar seu lugar na sociedade.

De projetos articulados em alinhamento com o espírito do mundo conexionista, à afirmação de uma marca de uísque por meio da celebração da vida de seus garotos propaganda, o que apreendemos é uma leitura da transformação social que não promove fissuras nas bases do capitalismo hegemônico. Pelo contrário, muitas vezes renovam sua retórica, aos moldes do processo do espírito do capitalismo analisado por Boltanski e Chiapello (2009). Dessa forma, o empreendedorismo social emerge como discurso de engajamento, de incentivo à participação, que conota algo de transcendente, de magnânimo e elevado para seus agentes exemplares. Exemplos de sucesso, na releitura da polarização com o loser, o perdedor da cultura competitiva fundada no

\footnotetext{
8 A noção de regimes de convocação biopolítica, desenvolvida por Prado (2013), é baseada na teoria de Foucault. De acordo com Prado (2013, pp. 10-11), "no mundo contemporâneo há uma infinidade de enunciadores, que [...] nos convoca para programas específicos, apoiados em atividades e serviços oferecidos no mercado". Nesse sentido, os discursos sobre o empreendedorismo social não somente comunicam sobre essa cena, mas convocam os sujeitos à participação, ao engajamento para atuar em suporte a iniciativas exemplares, ou na concepção de novos projetos que seguem os seus modelos de sucesso.
} 
liberalismo. O poder de sedução desse discurso já é percebido como produtivo em termos de incentivo ao consumo; marcas como Chivas, Banco Itaú (o maior banco privado do Brasil e um dos maiores da América Latina, cuja estratégia publicitária recente reitera o discurso da 'transformação'), entre outras, investem em iniciativas para alimentar o capital simbólico de sua organização e de seus produtos.

Como defende Lazzarato (2006, p. 99), "a empresa que produz um serviço ou uma mercadoria cria um mundo"; no mundo de Chivas, a competividade é a regra e o sucesso o paradigma. O que é reiterado pelo seu mais recente projeto, o concurso The venture (o empreendimento), que atribui o prêmio de um milhão de dólares ao vencedor entre 13 países, incluindo o Brasil. Em sua apresentação, fica evidente a estratégia de cooptação da imagem do empreendedor social para a tradicional marca de uísque:

Chivas acredita que os negócios podem ser lucrativos e, ao mesmo tempo, ter impactos positivos na sociedade. Essa crença está no nosso DNA desde que os irmãos John e James começaram seus negócios em Aberdeen, Escócia. Acreditamos que essa é a hora para celebrar a generosidade de espírito e dar um novo significado ao sucesso no século 21. Por isso estamos procurando start-ups que usem o empreendedorismo para colaborar com o avanço do País. (Chivas, s.d.)

A marca de uísque, fundada no começo dos anos 1800, estabelece a si mesma como o marco zero, a gênese do espírito empreendedor social, pela 'generosidade' dos seus fundadores, seja lá o que isso quer dizer. Dessa forma, esvazia-se qualquer sentido transformador que a cena empreendedora social poderia representar, em um mundo em crise, em diversos sentidos - do econômico ao ambiental. Por mais que possa haver algumas iniciativas de empreendedorismo social louváveis, ficam as questões que nos intrigam: é possivel superar esse processo cultural de vampirização da ação social, ou de seu esvaziamento, pela retórica do capital? A transformação social é possível, sem que se assuma sua dimensão politica, e sem que se choque com interesses, privilégios e valores arraigados no modelo capitalista hegemônico? 
O projeto de sociedade empreendedora social é um discurso mítico, fundado na crença de que a cultura empreendedora é a única via para mudar o mundo, mesmo sem produzir transformações efetivas no sistema capitalista. Eis um paradoxo fundamental, amplificado pelo discurso, em tom positivo, que afirma a existência de uma revolução em curso, em escala global, promovida pelo empreendedorismo social.

\section{Referências}

Angenot, M. (2010). El discurso social: los limites históricos de lo pensable y lo decible. Buenos Aires: Siglo XXI.

Atados (s. d.) Disponivel em https://www.atados.com.br/sobre

Boltanski, L., \& Chiapello, Ė. (2009). O novo espírito do capitalismo. São Paulo: Martins Fontes.

Bourdieu, P. (2009). O poder simbólico. Rio de Janeiro: Bertrand.

Buonanno, M. (2011, jul/dez). Histórias de vida exemplares. Biografias. MATRIZes, 5(1). 63-84.

Favor añadir la siguiente referencia: Cabral, F., Campanatti, M., Ribeiro, M. y Pereira, T. (s.f.). Imagina na copa. Disponivel em: http://imaginanacopa.com.br/.

Casaqui, V. (2014). Ideologia do empreendedorismo social: representações do trabalho em tempos de crise do Estado Social português. Rumores, 8(16), 19 36 Disponível em: http://www.revistas.usp.br/Rumores/article/view/89636

Chivas (s. d.). Live with Chivalry. Disponivel em: http://www.chivalryclub.com. $\mathrm{br} / \mathrm{chivas}$ / campanhas/temos-um-milhao-de-dolares-para-investir-em-ideiasque-promovam-mudancas-positivas-na-sociedade?utm_source=facebook\&utm medium=campanha\&utm_campaign=vencadojeitocerto\&utm_content=theventure 
Chivas Regal (2014, nov 4). Vença do jeito certo. Disponivel em: https:/ / www. youtube.com/watch?v=SIH1CMxHmcI

Chivas Regal Brasil (2010). Chivas Regal Brasil Facebook Fan Page. Disponivel em: https://www.facebook.com/ChivasRegalBrasil

Drucker, P. F. (2011). Inovação e espirito empreendedor: prática e princípios. São Paulo: Cengage Learning.

Ehrenberg, A. (2010). O culto da performance: da aventura empreendedora à depressão nervosa. Aparecida - SP: Idéias \& Letras.

Fairclough, N. (2001). Discurso e mudança social. Brasília: Ed. UNB.

Lazzarato, M. (2006). As revoluções do capitalismo. Rio de Janeiro: Civilização Brasileira.

Lopes, M. (2012). Verbete "Empreendedorismo". Em Dicionário das crises e alternativas (pp. 86-87). Coimbra: Almedina, CES.

Morin, E. (2011). Cultura de massas no século XX - Vol 1, Neurose. Rio de Janeiro: Forense Universitária.

Polanyi, K. (2012). A grande transformação: as origens da nossa época. Rio de Janeiro: Elsevier.

Prado, J. L. A. (2013). Convocações biopoliticas dos dispositivos comunicacionais. São Paulo: Educ / Fapesp.

Projeto Sonho Brasileiro. (2011). Pesquisa realizada pela agência Box1824. Disponivel em http://pesquisa.osonhobrasileiro.com.br/indexn.php

Quintão, C. (2012). A reemergência do Terceiro Setor. Em L. Veloso e R. M. Carmo (Orgs.). A constituição social da economia (pp. 123-153). Lisboa: Ed. Mundos Sociais. 
Schumpeter, J. A. (1961). Capitalismo, socialismo e democracia. Campinas: Fundo de Cultura.

Stanford Social Innovation Review (s.d.). Disponivel em http://www. escoladesignthinking.com.br/inovacaosocial/

Weber, M. (2004). A ética protestante e o "espírito" do capitalismo. São Paulo: Companhia das Letras.

\section{Cómo citar este artículo}

Casaqui, V. (2016). A transformação social nos discursos da cena empreendedora social brasileira: processos comunicacionais e regimes de convocação na mídia digital. Universitas Humanística, 81, 203-226. http://dx.doi.org/10.11144/ Javeriana.uh81.tsnd 